\title{
Restoration and Development of Urban Heritage Sites (Rehabilitation of Middle cities and Heritage towns)
}

\author{
Dr. Esraa Ahmed Aboushal \\ High Institute of Engineering and Technology (BHI),Architectural Department,Egypt. \\ Esraaaboushal1@gmail.com. Cell Phone: $(+2) 01289931406$ \\ Dr. Mohamed Salah Gharib \\ High Institute of Engineering and Technology (BHI ),Architectural Department,Egypt. \\ mohds69@gmail.com Cell Phone :( +2) 01222640690
}

\begin{abstract}
There are various restoration methods and techniques that would help specialists whether planners, designers and archeologists to study historical sites and their valued heritage buildings in various cities at Egypt as Alexandria governorate which is considered as one of heritage towns. One of these techniques is Virtual Reality (VR) that could be used to improve the field of Virtual Heritage (VH) which is directed towards accurate representation of historic structures in urban heritage sites, objects or artefacts. Beside, using Geographical Information System (GIS) and Google earth model to define these urban heritage sites accurately with all database related to the specific area under study. Digital models of historical buildings and its urban spaces only give a sense of precision for their historical values. Yet, human attitude and cultural traditions remain a gap in current research and advanced technology in heritage visualization. So, Virtual Heritage Environments (VHE) suffers from the lack of 'thematic interactivity' due to the limited cultural heritage content and engaging modules largely used in photorealistic systems. So, this paper focuses in using various digital restoration techniques and methods to investigate and incorporate a cultural-feed into digital platforms of $\mathrm{VH}$ especially at Alexandria in Egypt as Qaitbay castle plaza.

This site discusses a conceptual and practical workflow for the development of virtual heritage platforms as a research area, educational purpose. The study includes engagement tool of historic conservation in Alexandria, brings historic spaces and buildings to users in detailed studies whether researchers or students.
\end{abstract}


The results of the research would be used for the renewal of the current plaza of Qaitbay castle by making it more attractive. Also, this plaza is considered as a tourist and historical area as well as the organization for paths of movement and transforming the work places for sale from street vendors to organized markets. The scenario was realized by integrating low-cost Virtual Reality (VR) techniques, as the Kolor Panotour Pro software, some tools as Oculus Rift DK2 and the Leap Motion controller. Further, the 3D virtual model was implemented by integrated steps through Virtual Tours and Informational Modeling (VT/IM) to improve real urban data of heritage sites.

The paper describes the process for optimizing the 3D virtual model, the implementation of the interactive scenario and the results of a proposed 3D VT/IM of redesigning model for the Qaitbay Castle Plaza. Finally, the paper predicts future research directions for virtual reality, with a particular focus on interaction interfaces and explores the implications for the cultural heritage domain.

\section{Keywords}

Virtual Reality (VR); Virtual Heritage; Virtual Environment (VE); Digital Archaeology; Historic building information model (HBIM), Urban Heritage; Virtual Tours and Informational Modeling (VT/IM); Mixed Reality (MR), Augmented Reality (AR); Geospatial Reference, Geographical Information System (GIS) and Google earth model.

\section{Introduction}

The preservation of digital cultural heritage has become an international priority, and the area Virtual Heritage Area ( $\mathrm{VH})$ has long been concentrated on generating digital reconstructions of archaeological artefacts and urban heritage sites. This generating is achieved with sufficient accuracy to represent the urban heritage sites counterparts in the real world, whether to develop or rehabilitate those sites (Denker 2016). In this regard, the developing of VHE could be concerned in upgrading architectural educational specially the architecture history using VR technology as AR and MR technologies for different purposes, including exploration, reconstruction to be evaluated, improved the learning experience and engaged with the modern generation of students (Abdelmonem et al. 2017). In some cases, the advancement of tools and techniques for achieving greater visual realism has distracted from the development of other directions that enhance a virtual experience, such as interactivity, sound or touch. Much of the effort in $\mathrm{VH}$ is directed towards accurate representation of historic structures, objects or artefacts. It is noteworthy to improve virtual fidelity and accurate reproduction of historic environments. So, planner should redesign the urban heritage sites using new digital technologies and methods such as comprehensive methods of Virtual Tours and Informational Modeling (VT/IM) according to proper principals of design that should be considered. 
Hence, strategies, practices and technologies that can protect and sustain the urban heritage sites in other forms of reproduction such as digital modeling, Mixed Reality (MR), Augmented Reality (AR) and cinematography have been key aspects of cultural heritage preservation over the past decade (Frost and Warren 2000).

These technologies enable user centered presentation and make cultural heritage digitally accessible, especially when physical access is constrained.

Beside, Virtual Environments (VE) which encompass cultural heritage offer the possibility to experience virtually reconstructed historic sites as specialists whether planners or archeologists or public visitors. Additionally, it is important to enhance the perception of urban heritage sites by analyzing its urban features, the need of upgrading these sites to be smarter and as advanced tourism areas to be also more attractive point in heritage towns with interactivity. This approach is illustrated in this research by redesigning a case study of Qaitbay castle plaza in a virtual model. This model develops a prototype of Virtual Environment (VE) that is created for specialists as well as public users. Therefore, several studies demonstrate that the use of new technology as VH enhances how culture heritage is experienced specially in improving not only the developing of urban heritage site but also the architectural education such as lectures of architecture history (Kaufmann, Schmalstieg, and Wagner 2000). This hypothesis is achieved by immersing students into specific VE and allowing them to learn by browsing through it and interacting with the virtual model to study and evaluate it. Moreover, allowing students to propose various design alternatives to upgrade the valued historical sites keeping pace with modern technologies. So, they can be more engaging and motivating than simply reading the corresponding history text or watching an educational video (Sánchez, Barreiro, and Maojo 2000). The outcomes of the study suggest a new proposal for redesigning the case study area in a virtual model to be more attractive tourist area that would increasing the national income of one of a conservation site in Alexandria, Egypt.

Firstly, planner should define the study area and the urban requirements by relying on the information of the historical plaza through surveying process. Secondly, planner defines the problems in the study area to overcome them accurately which can be extracted from the planning and architectural decisions by planner. Thirdly, proposing a virtual model of redesigning the study area by modeling the new plaza using the method of VT/IM. So, the virtual model would include all needed services such as shops, cafeterias, cafes and appropriate seating areas at a public historic plaza. Beside, improving the design of patterns in current path that lead to the Qaitbay castle plaza. Hence, the new design for the public historic plaza of Qaitbay castle is well defined accurately whether from the side of design or from the geospatial defining, where the analysis results are incorporated to the site' database using ArcGIS software. 
This way, the proposed virtual model would be helpful to specialists or architectural students.

Thereby, the output virtual model will achieve various points as, conservation report of real site accurately, a new comprehensive georefereanced database and controlling virtual tour to evaluate the proposed Qaitbay castle plaza.

\section{Research Objectives and Organization}

The objectives of this research are how to utilize commoditization for the conservation and promotion of cultural heritage in rehabilitation of middle cities and heritage towns as Qaitbay castle plaza by developing interpretative strategies, specifically enabling access to intangible cultural heritage through its tangible parts. Therefore, this research is based on three main and important ideas as presented in Fig.1:

- Restoration Techniques.

-Developing VH.

-Re-planning Cultural Heritage Sites.

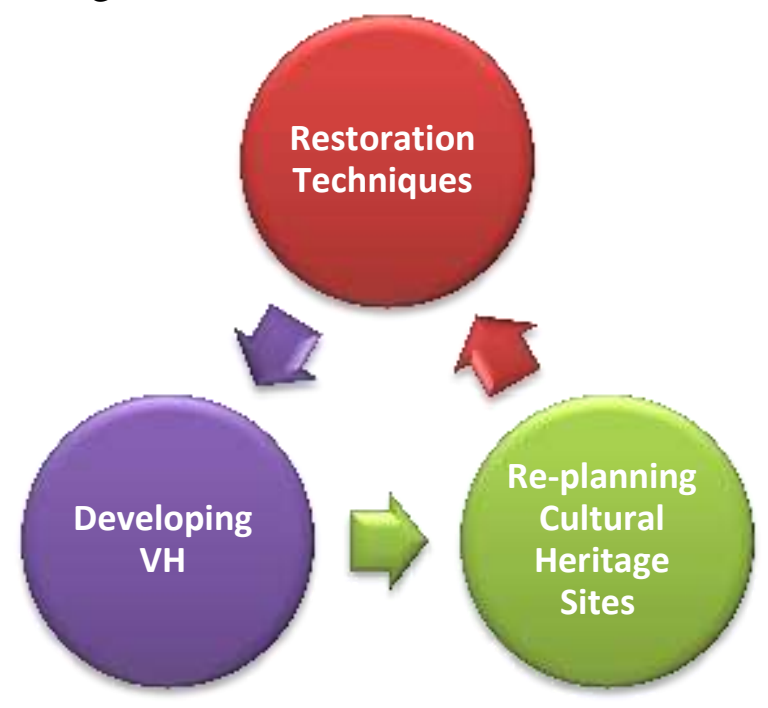

Fig.1: The relationship between the three main ideas in the research.

In the light of the above mentioned motivations, this paper introduces an effective redesigning of the public historical plaza at a given Qaitbay castle area based on the design criteria. In addition to, specifying the urban problems to overcome them at the studied plaza. In this direction, a dedicated case study is proposed for implementation of the proposed method in three ultimate stages as discussed hereinafter. The first stage seeks identification of the study area and all urban features using ArcGIS and Google Earth software. For this purpose, a Geo-Model is introduced to analyze the spatial data of the studied area. It uses Google Earth imagery as a base map in ArcGIS software. 
This analytical tool ensures precise results by knowing the various levels in the study area, topological relationships specially between the path on plaza and the castle buildings considering the design principles and various environmental conditions.

Whereas, in the second stage, putting defined virtual schema mapping by integrating geospatial maps then, specifying and analyzing urban functions after that, producing and validating of design studies for upgrading the study area in. This is performed by modeling a virtual proposal and immersing users on it as presented in Fig.7, Fig.8, where the model considers the design in line with environmental conditions.

Finally, in the last stage, the obtained results are jointly gathered and inserted to the buildings' database in ArcGIS software that integrated to the proposed virtual model. They include the design characteristics of the public urban heritage plaza, the appropriate services, the specified potential areas of seats according environmental conditions like shading, clouds and ambient temperature. In summary, this paper proposes a new method based on the urban local possibilities and funding based on the consistency with the studied site location. In this way, planning of future sustainable urban heritage site could be enhanced without negligence of the necessary environmental treatments related spatial analysis.

\section{Methodology of the Research}

In this section, the research methodology is presented through three main stages which adopted for the implementation of the proposed method.

\section{The first stage}

Identification of the surveyed areas in Google Earth Software.

- Step (1): Analytical study of determination of site' location and buildings around the site.

- Step (2): Visualizing 3D building model of Qaitbay castle in a red zone in Google Earth Software with all georefereanced database tables in a KML format as shown in Fig.5/ below.

- Step (3): Analysis of Qaitbay Castle as a one of the most important fortifications in the Islamic era.

- Step (4): Defining the pedestrian link between the project site and Qaitbay Castle.

- Step (5): Analyzing the visual openness and a variety of visual angles between the sea and Qaitbay Castle plaza.

The second stage

Geo-model produced by different steps in ArcMap software that are integrated together in order to determine the best suitable georefereanced model. 
- Step (1): The integration database between the ArcGIS and Google Earth model of Qaitbay castle plaza.

- Step (2): Visualizing Geo-Virtual model in a base Map of Qaitbay castle layout in ArcMap software according to WGS1984.

- Step (3): Determination of the orientation site' and various levels of plaza according to georefereanced definition in ArcMap software.

- Step (4): 3D Geo-Model is introduced to analyze the urban features in the plaza and its spatial relation to the studied Qaitbay castle buildings.

\section{The third stage}

Virtual model is produced by modeling the Geo-model in VE at the Kolor Panotour Pro software. It focuses on data gathering and insertion of the obtained results to the buildings' database in ArcGIS software, including the appropriate patterns of the redesigned path, specified potential areas of seating areas' parameters according to environmental conditions like shading, clouds and ambient temperature from ArcMap software.

\section{Rehabilitation of Heritage towns}

The research deals with the study and analysis for the applications of VR and GIS used in redesigning and improving rehabilitation of heritage towns with the studies of 3D survey in real site in defined urban heritage site as Qaitbay castle plaza by studying the following:

A. Survey Strategy: Studying the 3D urban heritage sites.

B. Management Features of Urban Heritage Sites: The study analyzes and visualizes various historical elements. This is according to registering legal status, attributes and rights.

C. 3D Surroundings Environment: It is also a comprehensive concept that integrates surroundings: lands, houses, shops with 3D data, parties and human behaviors.

D. The Modeling Process: The proposed model based on the redesigning the study area according to design constrains and principles by navigating into VE and evaluate it.

E. The Spatial and Environmental Analysis: It could be achieved for the defined study area in ArcMap software. 


\section{Using Technological Methods in Developing of Urban Heritage Sites}

There are various technological methods for documentation, communication of conservation data and in developing of urban heritage sites. Conservation challenges are documented and recorded using 2D methods, such as digital mapping, or 3D methods, such as Photogrammetry, laser scanning and building information modeling (BIM) that could be used for tourism, education or structural analysis. Where Photogrammetric is the process of digitally stitching together over-lapping 2D images to generate a 3D model. Laser scanning emits laser to the surface of a sites and its buildings, tracks the time needed for travel and reflection and then creates a dense 3D cloud of points representing the structure. While, BIM enables 3D models to have inter-active links with relevant data. (Eastman et al. 2011). Each of these approaches is useful for conveying data relevant to conservation challenges; yet, it is important to understand that the selected method must be appropriate for a project's scope, timeline and budget constraints.

In this paper, it could be used another digital techniques as a simulation tool for visualizing of the urban heritage sites using VR Systems as Augmented reality system (AR) in a VT/IM that integrates with 3D survey system using 3D laser scanning technique. Furthermore; these digital techniques could be used for achieving the production of 3D virtual models on historical sites (Jusof and Rahim 2014). A study summarizes the strengths and possible extensions of the proposed system. Besides, there are various tools used in the study area that could be used also to improve architectural education (Fig.2) such as:

a. A stereoscopic head mounted display (HMD).

b. The Personal Interaction Panel (PIP): It includes a two-handed 3D interaction tools that simplifies 3D model interaction.(Anon n.d.)

c. Historic building information model (HBIM).
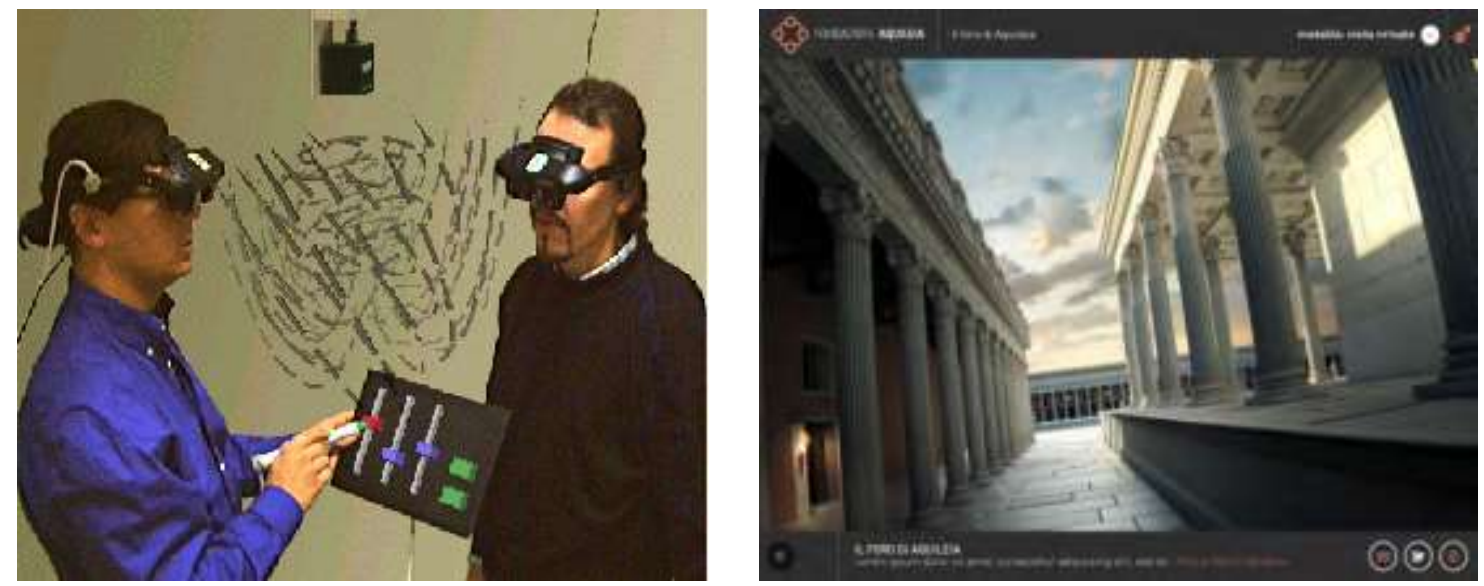

Fig.2: Using HMD and the Personal Interaction Panel (PIP) in architectural Education at the lectures of architecture history. 


\subsection{Methods for Documenting the Historical Site}

The reconnaissance documentation is applied by surveying the real site and taking a photographic surveying the details in site and then drawing the layout by architectural drawings to understand the overall characteristics. (Letellier and Eppich 2015) This preliminary documentation generates various graphic records that highlight a site's major features in scaled form. This documentation can be used for conservation of historical projects and preliminary analysis based on the works is presented in Fig.3. Another method is VT/IM which is a method that can only be used for developing informed cultural heritage projects, and augmenting the conservation which reflects a high cultural value of site while taking into consideration the funding aspects that should be firmly considered (Koehl and Brigand 2012). Beside, Informational modeling (IM) is an approach that involves managing and visualizing digital representations of data; this approach can be facilitated through user interactions within the VT data so, they can view the latest conservation report within the immersive VT environment that can aid communication between a conservator and a studied building. Presently, no VT/IM workflow exists for building conservation. In this initial study, the research provides a workflow for future implementation of VT/IM and tests it on a case study. This workflow is appropriate for conservation projects where initial documentation of 3D conservation issues is essential, but a $3 \mathrm{D}$ model is outside the current budget and time constraints. Further, it should be noted that research follows on using integrated digital technologies as Historic building information model (HBIM) for the future architectural rehabilitation \& conservation of historical site.

BIM have been used to study a 3D model that outlines a method for creating a historic HBIM from laser scan point clouds (Percy et al. 2015). Yet, due to the high costs of laser scanners and BIM software, this approach is not implemented widely. While Photogrammetry can generate point clouds at a lower cost, they still have large data files that require further allocation of time and money for data management (Dore and Murphy 2015). So that, the VT/IM method is the most appropriate method that could be applied in this research.

\subsection{Levels of Detail for Documentation (LOD)}

It is important to recognize that VT/IM falls under the category of "initial recording" level and should not be used for detailed recording. As stated in recording documentation and information management for the conservation of heritage places so, there are three main levels of detail for heritage documentation:

-Initial/reconnaissance recording.

- Preliminary recording.

- Detailed recording. (Letellier and Eppich 2015) (Garagnani and Manferdini 2013). 
Table.1: Illustrating the levels of documentation for heritage structures.

\begin{tabular}{|c|c|c|c|}
\hline $\begin{array}{c}\text { LOD for Recording } \\
\text { Heritage Structure }\end{array}$ & $\begin{array}{c}\text { Initial } \\
\text { reconnaissance }\end{array}$ & Preliminary & Detailed \\
\hline $\begin{array}{c}\text { Aims of recording } \\
\text { heritage structure }\end{array}$ & $\begin{array}{c}\text { Initial planning } \\
\text { communication } \\
\text { reference }\end{array}$ & $\begin{array}{c}\text { planning Initial } \\
\text { condition pre-design }\end{array}$ & $\begin{array}{c}\text { As founded condition } \\
\text { construction posterity }\end{array}$ \\
\hline Time required & 1 day -1 week & $1-3$ week & $\begin{array}{c}3 \text { week and } \\
\text { continuous }\end{array}$ \\
\hline
\end{tabular}

\section{The Proposed Case Study}

The study zone is located in Alexandria governorate at Egypt in the Gomrok District. It is bordered by the Alexandria Mediterranean Sea. From the east, the study zone overlooks El Geish Road and its total area is about $43622 \mathrm{~m}^{2}$ as presented in Fig.3.

\subsection{Analytical Study of Qaitbay Castle}

Qaitbay Castle is one of the most important archaeological buildings in Alexandria as illustrated in Fig.3. The main purpose in the research is proposing a new redesign of the study area including organized path to the castle according to the current urban features and the buildings around the site based on the proper design principles as shown in Fig.7 and Fig.8. 

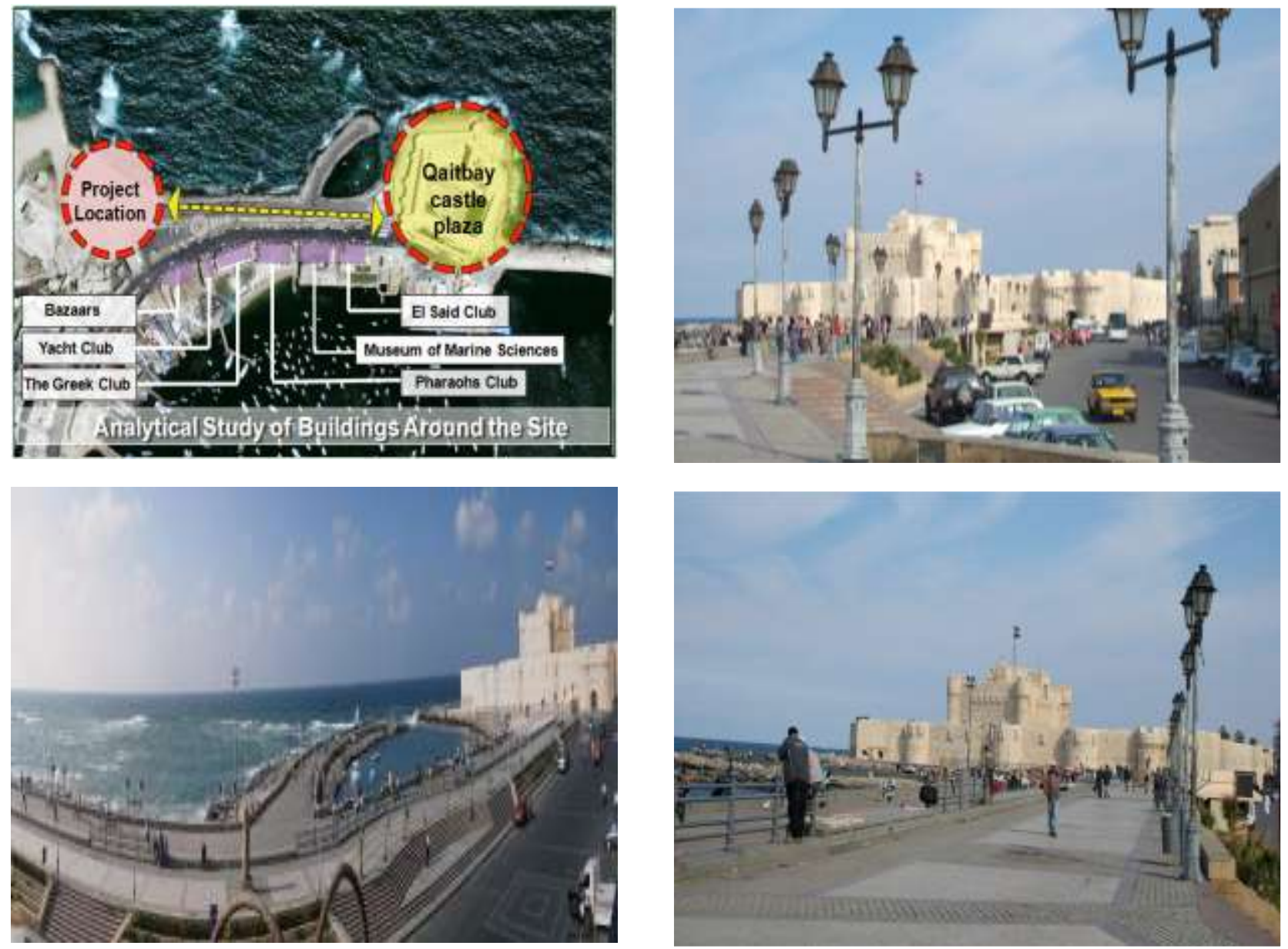

Fig.3: Analytical Study of Qaitbay Castle.

Top Left: Defining the site location and the buildings around in Google Earth software.

Top Right: The castle is visually clear from the project site and it is one of the most important fortifications in the Islamic era.

Below Left: Analyzing the visual angles between the sea and Qaitbay Castle at a panoramic view of the project site.

Below Right: The pedestrian link between the project site and Qaitbay Castle.

\subsection{The Real Urban Problems in the Study Area}

There are many urban problems in the study area due to the lack of proper planning to the public plaza and the distribution of organized public services such as, shops, cafeterias, cafes and appropriate seating areas at this defined historical plaza that could be presented in Fig.4 (Below). Also, there is a lack of green spaces that are outlet for the study area. Besides, the lack of beautiful and organized flooring patterns according to the design requirements and the Egyptian code. There is also lack of places of gathering users that make social transactions and improve the place to be more tourist, attractive and investment. 

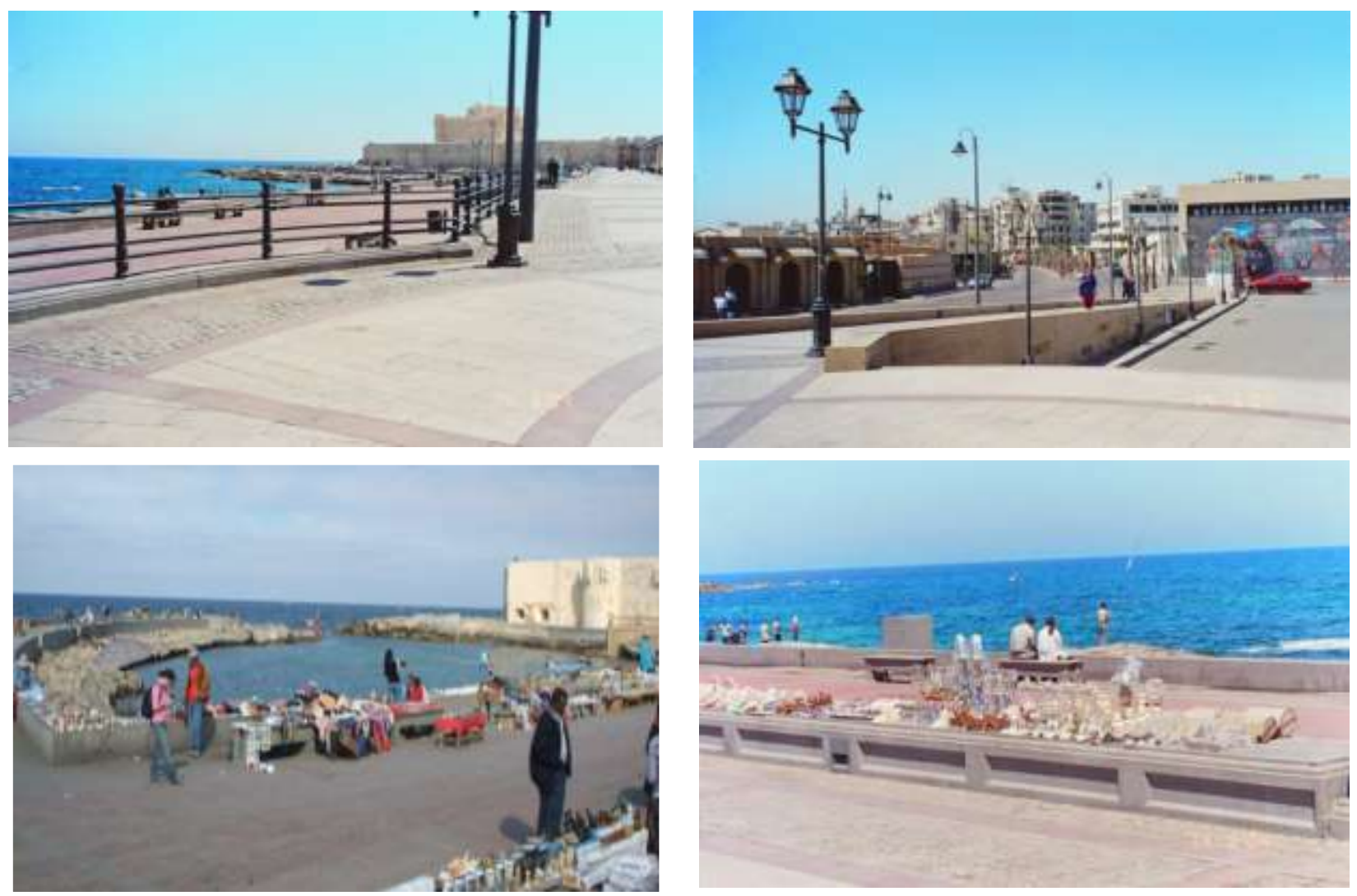

Fig.4: The Real Urban Problems in the Study Area.

Top: The pedestrians path that lead to Qaitbay castle plaza in various levels.

Below: Random path in the study area with illegal violations of street vendors in Qaitbay castle plaza.

\subsection{Digital Methods Used in the Study Area}

Planners can generate a virtual model of current study area to analyze the characteristics of 3D VT/IM model which facilitates communication and concerns with analyzing the accurate detailed initial recording of historical documentation as a digital mapping of site, reports of unorganized usage. Moreover, VT/IM provides much better capabilities for management, analysis and visualization for various data needed of virtual model in an integrated system. This study would benefit different stakeholders such as; expert urban planners, archaeologists and different local authorities. Moreover; the virtual model of the study area of Qaitbay castle plaza can be generated through some issues such as; input data that leads to generate a 3D virtual model with defining the requirements of data, technical considerations to produce $3 \mathrm{D}$ collaborative environments. Appropriate software automates converting images to panoramas and expedites making the VT using Kolor Panotour Pro software, which used successfully for documenting the proposed urban historic site. 


\subsection{Designing the Interface of 3D VT/IM}

The interface of 3D VT/IM illustrates how different areas of a 3D conservation challenge connect. Firstly, studying the urban features relations by analyzing the geographical symbology of the redesigned current plaza, its patterns in the path to the castle, the 3D building of Qaitbay castle. Also, the research presents how these urban features are connected accurately according to geospatial reference and spatial relationships through the integration database between the ArcGIS and Google earth model as shown in Fig.5. As a starting point, VT/IM could perform tasks such as digital mapping of different areas in site where unplanned current plaza exists and provide further redesign proposal about it. Besides, a user can view test results and databases virtually through a method of navigation, a user can move through the VT/IM as idintified in Fig.5. The embedded maps are interactive so if a user is familiar with the geography or layout of the buildings, they can use this to navigate to a certain perspective.

Each of the red zone in Fig.5, Bellow is where a 3D model of Qaitbay castle was identified with georefereanced database that was imported from ArcMap software with the georeferenced layout of the buildings. So, a user can navigate to specific locations in the VT/IM by name.

Moreover, the interface of 3D VT/IM tests a comprehensive design of a 3D virtual model in order to enhance and develop its current functions. This comprehensive design can be achieved by applying a proposed new conceptual workflow of an integrated system based on various software as ArcGIS and Panotour Pro on a current case study. It is an unplanned plaza that suffers from informal planning and non-organized landscaping, appropriate seating areas with several urban problems and the lack of services in public plaza.

Moreover; planners can visualize 3D virtual model besides the production of a variety of spatial analysis that study all urban features in this 3D virtual model such as site analysis studies. These studies are Aspect of ground surface, environmental conditions like shading, clouds and ambient temperature from ArcMap software. Planners also can navigate in virtual model, determine the needs of users in public plaza and submit future vision about extensions of services. In addition to that, the 3D virtual model enables users to navigate into its urban features to study and modify them. Thus; the research illustrates these ideas with respect to the developments in heritage towns, especially Alexandria at Egypt where users can visualize, evaluate any 3D urban heritage sites and its urban problems to be enhanced in the real world as illustrated in Fig.5, Fig.6, Fig.7, Fig.8. 

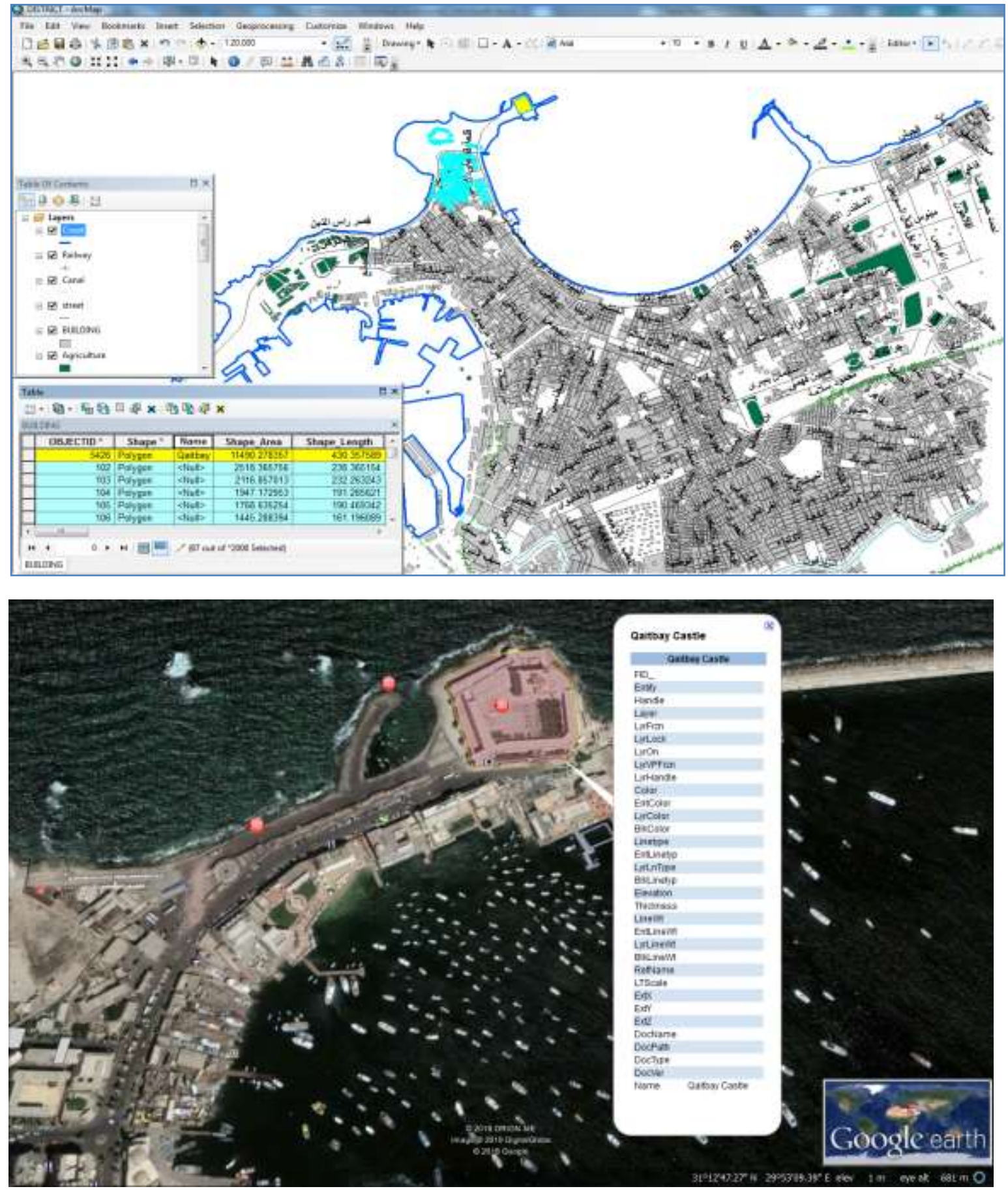

Fig.5: The integration database between the ArcGIS and Google earth model of Qaitbay castle plaza.

Top: Visualizing Geo model in a base Map of Qaitbay castle layout in ArcMap software according to WGS1984.

Below: Visualizing 3D building model of Qaitbay castle in a red zone in Google Earth Software with all georeferenced database tables from ArcGIS in a KML format. 


\subsection{Proposed 3D VT/IM Model of Redesigning the Qaitbay Castle Plaza}

Planners can visualize 3D VT/IM model by simulating the real urban area in a VE and study all urban features such as; the land uses and cases of current surrounding buildings and plaza to raise the level of services according to the environmental aspects so as to boost the services in the study area.

Besides, the study can be achieved by generating 3D VT/IM model consistent with a proposed conceptual workflow of an integrated system Fig.6 with a realistic representation of redesign the current study area. Further, the study would use a combination of spatial data and procedural rules in order to obtain accurate results as illustrated in Fig.7 and Fig.8.

\section{A. Suggested Workflow of Proposed 3D Virtual Model}

In this research, it could be created a VT/IM workflow to capture 3D urban problems and propose a new design to the real plaza to document and gather the relevant conservation data of historical site. The proposed workflow is created of an integrated system to investigate the integration of the parametric and procedural modeling from different comprehensive geospatial data formats of GIS, Google earth and virtual model through suggesting a new schema that can be seen in Fig.6. This proposal based on the characteristics of planning, available accurate data to support urban decision making even though not necessarily being a professional programmer or developer to improve and upgrade the design of 3D virtual model and study all its urban features.

Further, the workflow focuses on the process of developing the current historical site by simulating it in a virtual model. This could be achieved for various existing developments or proposed urban projects in the future to solve real urban problems such as unplanned public plazas. This process requires many steps that depend on each other to generate a smart and more sustainable 3D virtual model as shown in Fig.7, Fig.8 as follow:

\section{B. Steps of Generating the Proposed 3D Virtual Model}

There are many steps that depend on each other to generate the proposed 3D virtual model as follow in Fig.6:

1) Request Data: Urban data collection from real site survey.

2) Input Data: Planner starts to create a geodatabase in Esri ${ }^{\circledR}$ ArcGIS ${ }^{\circledR}$ software with unified coordinate system.

3) Processing Data: Secondly, export the latest geodatabase to Google Earth software to produce a 3D Geo-model. 
4) Role: Redesign (modeling virtual model via urban unified data) by updating this data regularly.

5) Output Data: This step is the most important one to integrate the previous four steps in one virtual schema mapping as a database connector. User can then extract a newly updated 3D VT/IM to be edited. Also, extracting a conservation report of real site through new comprehensive georefereanced Database. Finally, planner can control this virtual tour to present and analyze a current case study and its urban problems, then evaluate the proposed geospatial Qaitbay castle plaza.

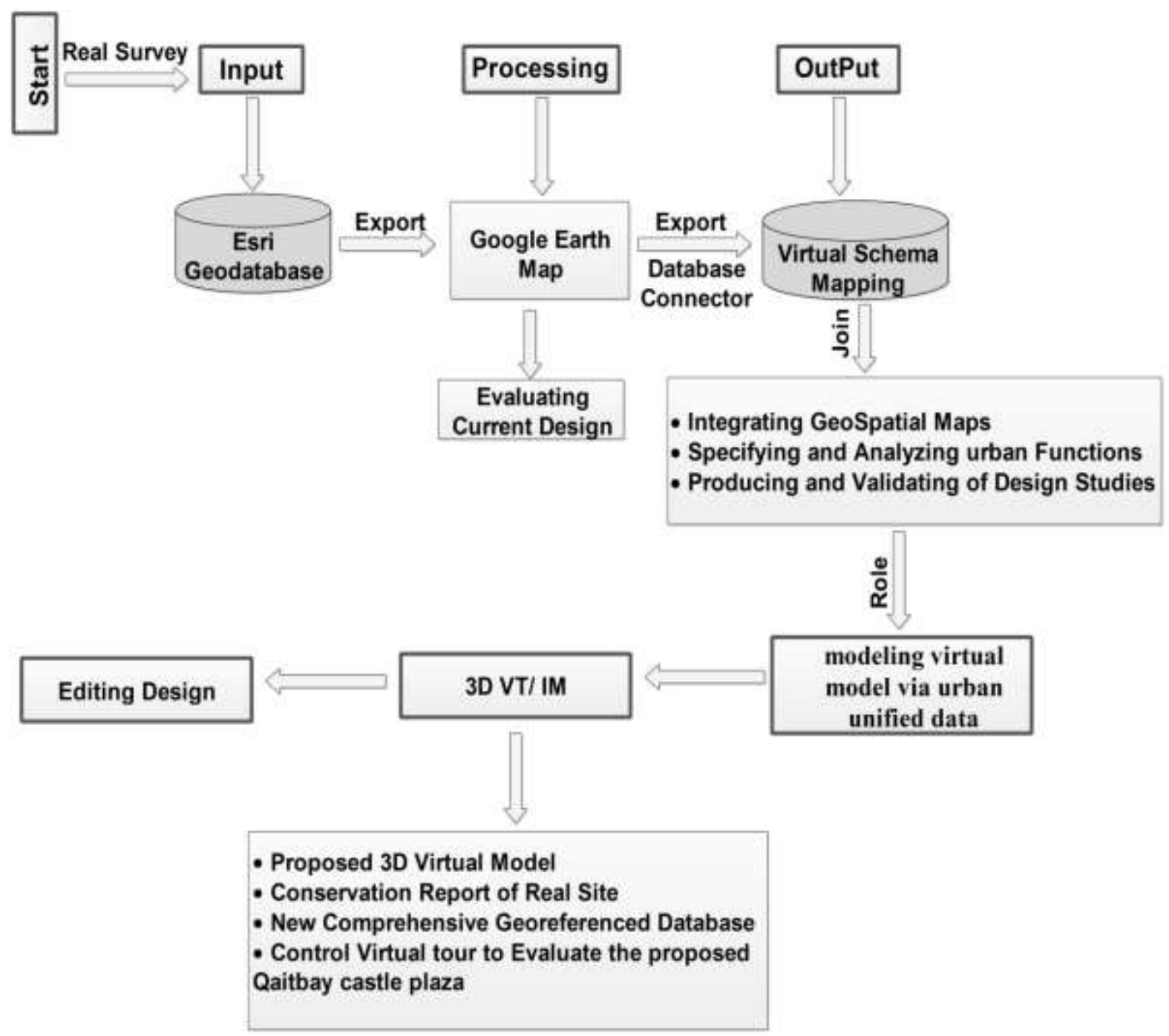

Fig.6: Suggesting a Workflow of Proposed 3D Virtual Model for documenting an urban heritage site. 

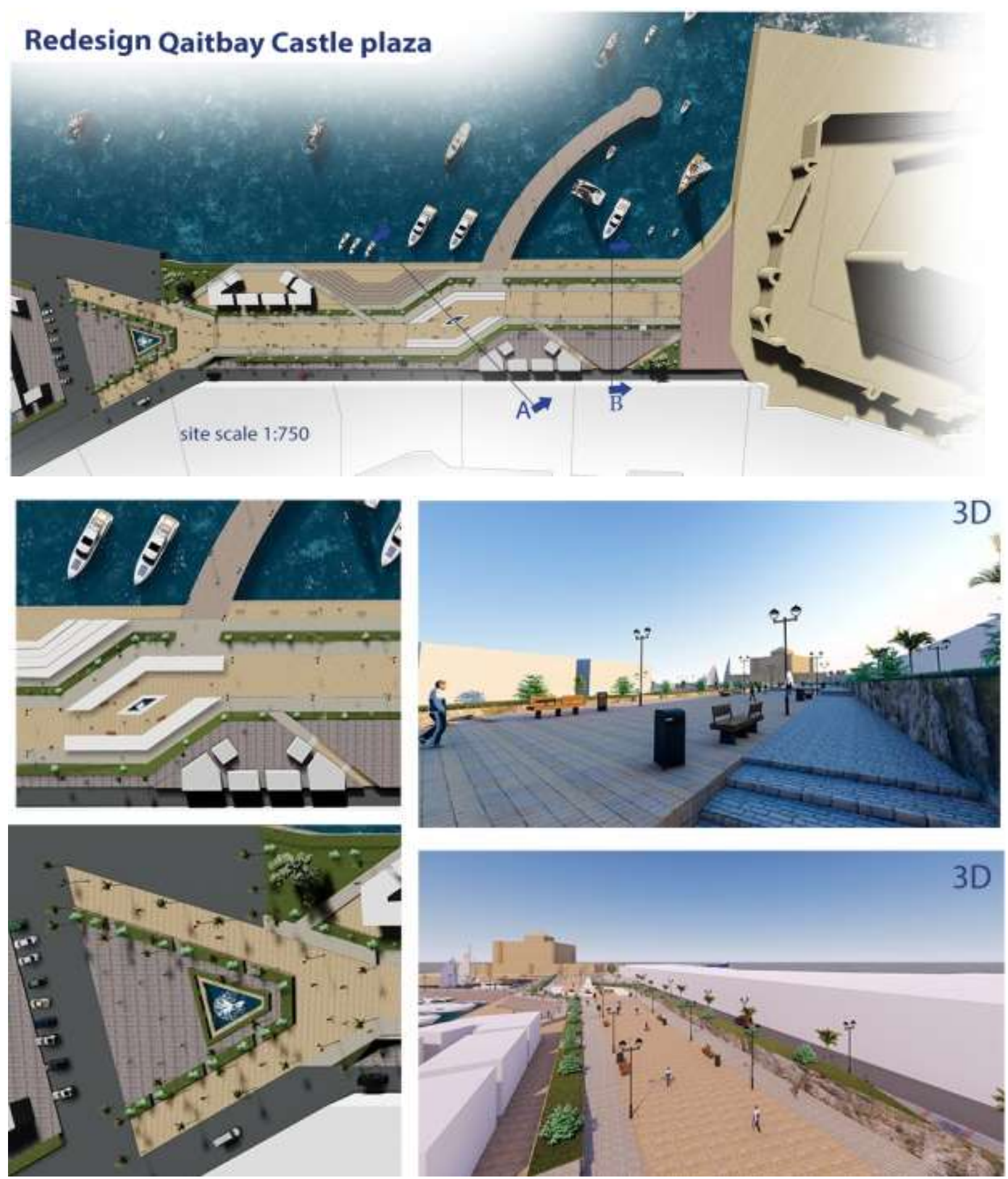

Fig.7: The proposed Interface of VT/IM model for redesigning of Qaitbay castle plaza.

Top: The proposed site plane for the Qaitbay Castle.

Below Left: the proposed paths with various patterns, landscape areas and various services as shops, cafeterias, cafes at a public historic plaza.

Below Right: The vision of Qaitbay Castle from all the visible visual angles. 

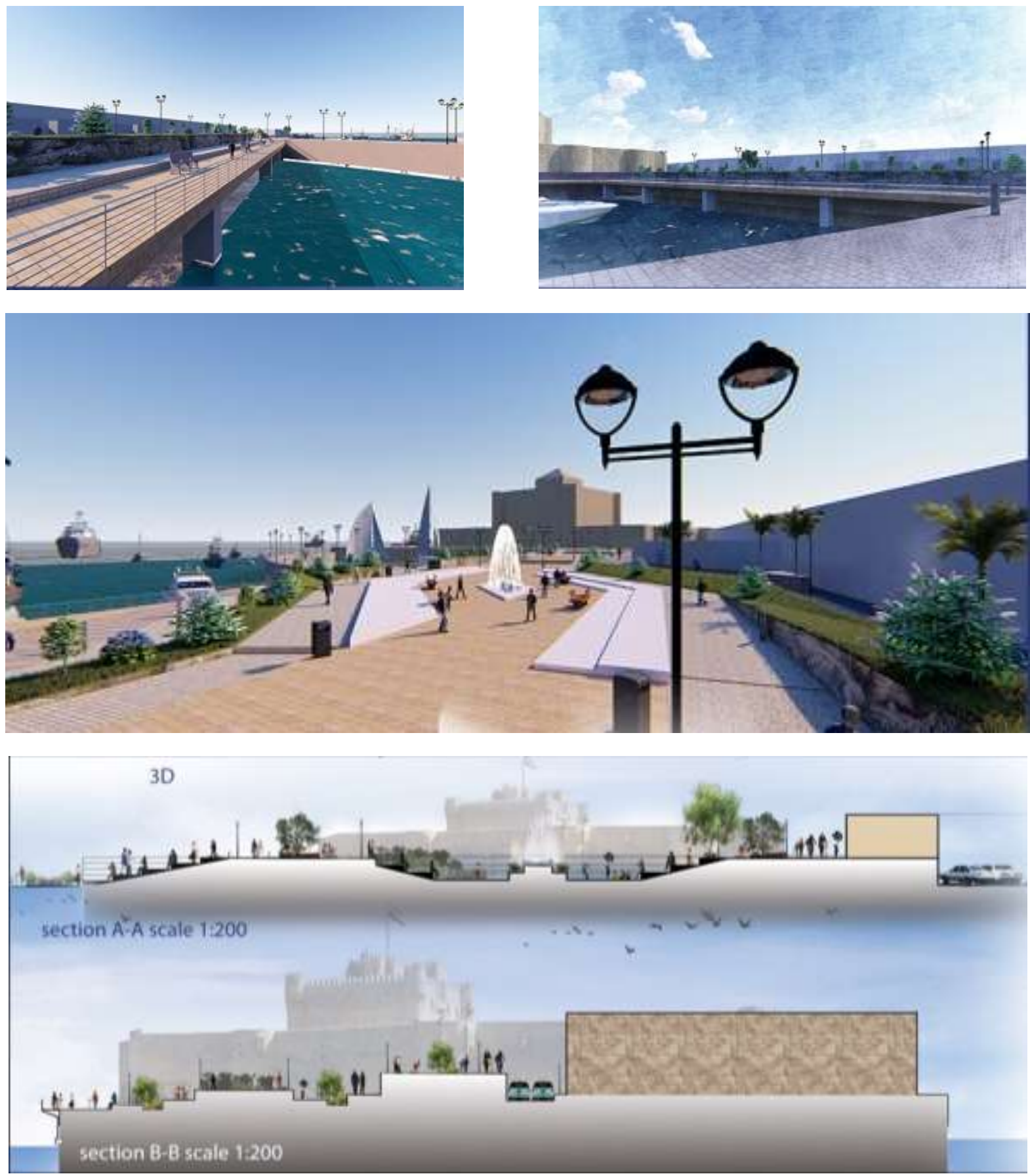

Fig.8: The proposal model of redesigning of Qaitbay castle plaza with various services and seating areas.

Top: The proposed paths with various patterns and landscape areas in various levels up to the Qaitbay castle.

Middle: A proposed symbol of seating areas in the study plaza.

Below: The proposed sections in Qaitbay Castle plaza illustrate all services and seats areas from all the visible visual angles. 


\subsection{Results and Discussion of Proposed 3D Virtual Model}

The result is an interactive VT/IM of 3D Qaitbay castle plaza compatible with using HMD and the Personal Interaction Panel (PIP) tools to navigate into VE and analyze it accurately. This virtual tour documents conservation problems around the real site and presents them in an interactive manner. So, VT/IM can fulfill the task of facilitating future communication between the current $3 \mathrm{D}$ historical building and the proposed plaza in a Virtual Environment (VE) with the help of geographic map to have a complete understanding of a structure and plan future interventions in the real site. In the VT/IM environment, a user can analyze the georefereanced database tables in a KML or GIS format based on the schematics and architectural drawings for the 3D model. This initial approach enables a conservator to interact with information when using BIM in future studies. In addition, a user can interact with 3D virtual model to overcome the unplanned current plaza and develop its services. Therefore, planner can create a VT/IM environment and document the historical site so easy of traditional survey and then drawing the proposed. Researcher can reach the fact that, the proposed 3D virtual model can be used in local level with the available possibilities in Egypt that are effectually applicable in improving the exchange urban data of heritage sites. Besides, planner can produce better proposals for different urban projects instead of the current methods used by all the competent authorities.

\subsection{Testing the Proposed VT/IM Model for Redesigning of Qaitbay Castle Plaza}

The proposed model has achieved various functional domains for generating 3D virtual model successfully. They are listed according to the functions of construction, capabilities, experiencing, controlling and interacting with the 3D virtual model Table.2.

Table.2: Various Functionalities for generating 3D Virtual Model Using a Suggested Workflow Schema.

\begin{tabular}{|c|c|}
\hline Construction & $\begin{array}{l}\text { - Data management role (data capture, storage and update). } \\
\text { - Data fusion, integration and manipulation: Multiple data format \& interface } \\
\text { and database within geospatial download software. } \\
\text { - Toolboxes: Controlling, navigating and movement tool. }\end{array}$ \\
\hline Capabilities & $\begin{array}{l}\text { - Presentation: Multiple scenes of different geometrical models, comparison of } \\
\text { old and new conditions of a defined study. } \\
\text { - Simulation for analysis and presentation. } \\
\text { - Feedback: Interactive cooperation between multi stakeholders. } \\
\text { - Output and upgrading data. }\end{array}$ \\
\hline Experiencing & $\begin{array}{l}\text { - Orientation and navigation aid. } \\
\text { - Manipulation, exploration and elaboration. } \\
\text { - Spatial analysis functionalities. }\end{array}$ \\
\hline
\end{tabular}




\subsection{Comparison of Methods}

Traditional methods did not fulfilled with desired purpose of developing urban heritage sites as using the VT/IM method in a VE for the conservation challenge. So, the research can compare the efficiency of the VT/IM method and highlights the performance of VT/IM for overcoming 3D problems in real site of unplanned plazas. The VT/IM approach in comparison naturally orients the user in a free angles and views to evaluate the real site and its urban problems. The VT/IM approach is helpful for planners to spend less time documenting the structure of the study area, less money on equipment with relatively small data files (2 GB). Additionally, VT/IM captures and conveys the built environment and associated 3D conservation data for a low cost in terms of data management too. So Planners can achieve any future urban project specially restoration and development of urban heritage sites with a more accurately using georefereanced database schema which are not available in existing methods.

\section{Conclusion}

This research has presented the ability to apply the proposed VT/IM model for redesigning of heritage sites on a case study model of the Qaitbay castle plaza in Alexandria governorate in Egypt. The unplanned area of Qaitbay castle plaza requires many improvements regarding functions by supplying the services and landscaping areas which are vital to users in public plazas.

Therefore, the VT/IM model is considered as a method for initial documentation, communication between various planners also as a generated 3D virtual model and as an interactive spatial system as well. VT/IM is efficient in terms of time, money, and data management; it provides new methods for modeling 3D virtual model using integrated software, documentation, management and analysis studies of urban heritage sites, topographical characteristics and environmental aspects. This method fills the void between the current methods of 2D digital mapping and Photogrammetry, laser scanning, and BIM depicted. For this study, efficiency was compared in terms of the time it takes to document the structure, the funds required and the size of the resulting data files. Besides, The VT/IM workflow illustrated can be used and adapted for future conservation projects and will aid users in conveying and understanding conservation problems in 3D. Moreover, the proposed VT/IM model would help different local authorities, expert urban planner, developers and archeologists to develop existing or future urban historical sites using spatial database, semantic modeling and analysis in GIS model. The users can interact with each other virtually; share all data with its attribute tables and all the properties of modeling via various georefereanced software.

Also; updating any information at any time in case of the occurrence of any urban changes in the real environment simply without reentering the information. Furthermore, 
the study has flexibility of design, evaluates the problems of unplanned plazas during evolution process of virtual model that can be tested and then implemented in the real world. Besides, allowing building realistic virtual models with freedom of movement between different angles, speeds, heights and level of details that not restricted to a certain time and place. Allowing the updating modifications of 2D and 3D virtual model, improving its design, functions, effects and simulating its form and size as real model. From this vantage point, planners can make multi comprehensive analyses and edits on virtual model via the proposed workflow schema. The latter can be used in the management, integration, presentation, evaluation and distribution of complex urban historic data which is based on georefereanced database. The study of some urban applications contributes to a comprehensive planning process that support expert urban planners in developing long term urban strategies which leads to boost the design process, analyses on the urban scale and creating a wider scope for more imagination and innovation. It is noteworthy that, the research outlines the overall concept of proposing a new conceptual workflow of integrated steps to contribute in resolving the issues of urban data for heritage sites for current and future urban studies according to the proper characteristics of planning.

\section{Suggestions and Recommendations}

1. The new technologies of VR and GIS should be used as digital techniques to simulate the urban heritage sites and its characteristics to enable users in visualizing the proposed projects to be upgraded in the real world.

2. The geodatabase could be used in all urban heritage projects to supply the stakeholders or specialists with full referenced data when they needed to study the status of every heritage project and take the appropriate design decisions related to them.

3. Using virtual model would enable users in a free navigation in VE to evaluate the characteristics of urban features whether in current or in the future heritage site with more imaginative and innovative skills.

4. Various users of expert urban planners, archeologists and local authorities should use new integrated technologies and software as tools or advanced methods to be applied for improving the current real or proposed urban heritage projects.

5. Using the virtual model in improving the field of virtual heritage would help planners to analyze the myriad of complex physical and social data needed to plan and manage any urban heritage site in the context of the urban heritage towns to be more appropriate for the public user's needs.

6 . The study of urban heritage development should be put into consideration, the important role of expert urban planners that should be enhanced during the studies of urban planning at existing cities such as; developing the future public historical sites especially unplanned. 
7. It should be putting a studied workflow of integrated methods to develop the current data of any urban heritage project by using GIS applications, VR technology with other advanced technologies regularly.

8. It is recommended to use proposed VT/IM to improve real urban data of heritage sites and support the process of redesign urban heritage sites, digital education and analytical research fields. This allows integrating data from different sources both spatial, descriptive, and contributes in decision making processes.

9. Universities should organize cultural sessions for planners, architects and specialists to update them with the latest technologies and new ideas to develop the field of urban heritage regularly by preparing virtual laboratories to upgrade the scientific research. 10. Architectural and planning departments in specialized universities should put planning for changing the traditional education methods especially in architecture history lectures to improve the skills of students.

\section{REFERENCES}

Abdelmonem, Mohamed Gamal, Gehan Selim, Sabah Mushatat, and Abdulaziz Almogren. 2017. "Virtual Platforms for Heritage Preservation in the Middle East: The Case of Medieval Cairo." International Journal of Architectural Research: ArchNet-IJAR 11(3):28-41.

Anon. n.d. "Studierstube Programmer's Guide." Retrieved December 27, 2018 (http://studierstube.icg.tugraz.at/stbintro/).

Denker, Ahmet. 2016. "VIRTUAL PALMYRA: 3D RECONSTRUCTION OF THE LOST REALITY OF 'THE BRIDE OF THE DESERT.'” Pp. 318-320 in 8th International congress on archaeology, computer graphics, cultural heritage and innovation. Editorial Universitat Politècnica de València.

Dore, Conor and Maurice Murphy. 2015. "Historic Building Information Modelling (HBIM)." Pp. 233-273 in Handbook of Research on Emerging Digital Tools for Architectural Surveying, Modeling, and Representation. IGI Global.

Eastman, Chuck, Paul Teicholz, Rafael Sacks, and Kathleen Liston. 2011. BIM Handbook: A Guide to Building Information Modeling for Owners, Managers, Designers, Engineers and Contractors. John Wiley \& Sons.

Frost, Peter and Peter Warren. 2000. "Virtual Reality Used in a Collaborative Architectural Design Process." Pp. 568-573 in Information Visualization, 2000.

Proceedings. IEEE International Conference on. IEEE.

Garagnani, Simone and Anna Maria Manferdini. 2013. "Parametric Accuracy: Building Information Modeling Process Applied to the Cultural Heritage Preservation." International Archives of the Photogrammetry, Remote Sensing and Spatial Information Sciences 5(1). 
Jusof, Muhammad Jafni and Hj Ruslan Abd Rahim. 2014. "Revealing Visual Details via High Dynamic Range Gigapixels Spherical Panorama Photography: The Tempurung Cave Natural Heritage Site." Pp. 193-200 in Virtual Systems \& Multimedia (VSMM), 2014 International Conference on. IEEE.

Kaufmann, Hannes, Dieter Schmalstieg, and Michael Wagner. 2000. "Construct3D: A Virtual Reality Application for Mathematics and Geometry Education." Education and Information Technologies 5(4):263-276.

Koehl, M. and N. Brigand. 2012. "Combination of Virtual Tours 3D Model and Digital Data in a 3D Archaeological Knowledge and Information System." Pp. 439-444 in ISPRS. Vol. 39.

Letellier, Robin and Rand Eppich. 2015. Recording, Documentation and Information Management for the Conservation of Heritage Places. Routledge.

Percy, K., S. Ward, M. Santana Quintero, and T. Morrison. 2015. "INTEGRATED DIGITAL TECHNOLOGIES FOR THE ARCHITECTURAL REHABILITATION \& CONSERVATION OF BEINN BHREAGH HALL \& SURROUNDING SITE, NOVA SCOTIA, CANADA." ISPRS Annals of Photogrammetry, Remote Sensing \& Spatial Information Sciences.

Psotka, Joseph. 1995. "Immersive Training Systems: Virtual Reality and Education and Training." Instructional Science 23(5-6):405-431.

Sánchez, Álvaro, José María Barreiro, and Víctor Maojo. 2000. "Design of Virtual Reality Systems for Education: A Cognitive Approach." Education and Information Technologies 5(4):345-362. 